\title{
Manejo do solo, palha residual e produtividade de arroz irrigado por inundação
}

\section{Soil tillage, rice straw and flooded irrigated rice yield}

\author{
Amauri Nelson Beutler ${ }^{*}$; Janete Denardi Munareto ${ }^{2}$; Ana Maria Fagundes Greco ${ }^{2}$; \\ Bruna Canabarro Pozzebon²; Leandro Galon³; Sérgio Guimarães²; \\ Giovane Burg²; Marcelo Raul Schmidt²; Evandro Ademir Deak²; \\ Robson Giacomeli ${ }^{4}$; Gibran da Silva Alves ${ }^{1}$
}

\section{Resumo}

O objetivo deste trabalho foi avaliar o efeito de sistemas de manejo e da palha residual na produtividade de arroz irrigado por inundação. $\mathrm{O}$ delineamento experimental foi inteiramente casualizado, com três experimentos e, dez repetições nos experimentos 1 e 2 e, 6 repetições no experimento 3 . Os experimentos foram: E1 - sistema plantio direto (E1PD) e sistema convencional com duas gradagens na camada de 0,0-0,07 $\mathrm{m}+$ aplainamento com remaplam (E1PC), em área de três anos de cultivo de arroz, após pousio do cultivo de arroz e semeadura de azevém no inverno, com pastejo animal o ano todo; E2 sistema plantio direto (E2PD) e sistema convencional (E2PC), após campo nativo; E3 - plantio direto com ausência de palha na superfície do solo (E30P), palha atual na superfície do solo de $3.726 \mathrm{~kg} \mathrm{ha}^{-1}$ (E31P), duas vezes a quantidade de palha atual, $7.452 \mathrm{~kg} \mathrm{ha}^{-1}(\mathrm{E} 32 \mathrm{P})$ e três vezes a quantidade de palha atual, $11.178 \mathrm{~kg} \mathrm{ha}^{-1}$ (E33P). No solo, foram avaliados o diâmetro médio geométrico dos agregados, a densidade, porosidade total, macro e microporosidade, nas camadas de $0,0-0,05$ e $0,05-0,10 \mathrm{~m}$. Na colheita, foram avaliados o número de panículas em área de $0,25 \mathrm{~m}^{2}$, número de grãos cheios, vazios e total em 10 panículas, massa de mil sementes e a produtividade de grãos de arroz em $2 \mathrm{~m}^{2}$. O sistema de manejo convencional apresenta maior macroporosidade e porosidade total do solo, comparado ao sistema plantio direto, porém, não resulta em diferença nos componentes de produção e produtividade de grãos de arroz. O manejo do solo em sistema plantio direto, com a quantidade de palha de arroz na superfície do solo de até $11.178 \mathrm{~kg} \mathrm{ha}^{-1}$, antes da semeadura, não reduz a produtividade de grãos de arroz irrigado por inundação.

Palavras-chave: Sistema convencional, plantio direto, restos culturais, rendimento, Oryza sativa

\begin{abstract}
The objective of this study was evaluate the effect of management systems and straw in flooded irrigated rice yield. The experimental design was a completely randomized with three experiments and, 10 replications in experiment 1 and 2 and, 6 replications in experiment 3 . The experiments were: E1 no-till system (E1PD) and conventional system with two harrowings at $0.0-0.07 \mathrm{~m}$ layer and leveling with remaplam (E1PC), after three years of sowing rice, after fallow of rice tillage, with sowing of rye grass in winter and grazing; E2 - no-till system (E2PD) and conventional system after native field
\end{abstract}

\footnotetext{
${ }^{1}$ Profs. Adjuntos, Universidade Federal do Pampa, UNIPAMPA, Campus Itaqui, Itaqui, RS. E-mail: amaurib@yahoo.com.br; gibranalves@yahoo.com.br

2 Discentes do Curso de Agronomia, UNIPAMPA, Itaqui, RS. E-mail: jdmunareto@gmail.com; amgreco@ymail.com; bru_ pozzebon07@hotmail.com; sergioguimaraessg@hotmail.com; gio_burg@hotmail.com; marceloraulschmidt@hotmail.com

3 Prof. Adjunto, Universidade Federal Fronteira Sul, UFFS, Campus Erechim, Erechim, RS. E-mail: galonleandro@ig.com.br

${ }^{4}$ Eng $^{\circ}$ Agr $^{\circ}$, UNIPAMPA, Itaqui, RS. E-mail: robsongiacomeli@unipampa.edu.br

* Autor para correspondência
} 
(E2PC); E3 - no-till without straw on soil surface (E30P), current straw on soil surface of 3,726 kg $\mathrm{ha}^{-1}(\mathrm{E} 31 \mathrm{P})$, two times current straw of 7,452 $\mathrm{kg} \mathrm{ha}^{-1}$ (E32P) and three times current straw of 11,178 $\mathrm{kg} \mathrm{ha}^{-1}(\mathrm{E} 33 \mathrm{P})$. In soil, were evaluated the average geometric diameter of aggregates, soil bulk density, soil porosity, macro and microporosity, in 0.0-0.05 and 0.05-0.10 m layer. In harvest were evaluated the panicles number in $0,25 \mathrm{~m}^{2}$ area, number of filled, empty an total grains in 10 panicles, mass of one thousand seeds and rice grains yield in $2 \mathrm{~m}^{2}$. The conventional system presented greater macroporosity and total porosity, compared with no-till system, however, does not result in differences in production components and rice grains yield. Soil tillage in no-till, with rice straw on soil surface up to $11,178 \mathrm{~kg}$ $\mathrm{ha}^{-1}$, before sowing, not reduces flooded irrigated rice grains yield.

Key words: Conventional system, no-till, cultural remains, yield, Oryza sativa

\section{Introdução}

O manejo do solo compreende um conjunto de práticas que, quando usadas racionalmente, promovem melhor produtividade das culturas, porém, quando usadas de forma incorreta, causam à degradação física, química e biológica do solo e, ainda, redução da produtividade. O manejo do solo por meio do sistema de preparo convencional (PC), a partir da década de 70 , tem induzido a um processo acelerado de degradação, com desequilíbrio de suas propriedades físicas, químicas e biológicas, afetando, progressivamente, o seu potencial produtivo. Entre os principais fatores de degradação dos solos, temse a compactação, redução da infiltração de água, da fertilidade e da cobertura vegetal, ocasionados pelo preparo excessivo do solo com arações e gradagens. Em substituição a esse sistema de manejo, o sistema plantio direto (PD), se adotado corretamente, é fundamental para mitigar o processo de degradação do solo e manter a qualidade do mesmo (COSTA et al., 2009).

$\mathrm{Na}$ fonteira oeste do Estado do Rio Grande do Sul, o arroz irrigado tem sido a principal cultura e atividade geradora de renda, visto que a economia é baseada no setor primário, com cultivo de arroz irrigado e pecuária extensiva. Este Estado responde pela produção de $61 \%$ dos grãos de arroz do país (SOSBAI, 2010), sendo o município de Uruguaiana o maior produtor nacional e, que, ainda, apresenta as maiores produtividades. Nesta região, o arroz tem sido cultivado predominantemente no PC, com arações e gradagens realizadas antes da semeadura, visando descompactar e nivelar o solo, controlar plantas invasoras, e acelerar a decomposição da palha residual do cultivo anterior, considerada prejudicial ao cultivo de arroz irrigado por inundação. Holanda et al. (2011) verificaram que a medida que aumenta o revolvimento do solo, diminui o teor de matéria orgânica. No entanto, o PC do solo tem custo elevado e necessita ser realizado anualmente, visto que os efeitos da descompactação na redução da densidade do solo tem duração inferior a um ano (SILVA et al., 2012).

O efeito nocivo da palha residual do arroz tem sido verificado pela produção de ácidos orgânicos que causam menor germinação, crescimento radicular, massa e altura de plântulas (SOUSA; BORTOLLON, 2002) e, menor produtividade do arroz irrigado por inundação (CAMARGO et al., 1995). Quantidades de palha de arroz acima de 6,5 t ha $^{-1}$ causam redução da produção de arroz em vasos, quando a água permaneceu estagnada (CAMARGO et al., 1995), porém, em PD, no campo, 24,6 t ha ${ }^{-1}$ de palha residual na superfície do solo, com $4 \%$ de declividade, não reduziram a produtividade de arroz irrigado por inundação (BEUTLER et al., 2012). Em PD, o excesso de palha na superfície pode limitar a produtividade, pois ocorre maior produção de ácidos orgânicos (JOHNSON et al., 2006). Entretanto, existem poucos estudos na literatura, de forma que a maioria dos produtores ainda utiliza o sistema de PC para fracionar, incorporar e expor os restos culturais do arroz a ação dos microrganismos e acelerar a decomposição, visando evitar a possível redução da produtividade, cuja magnitude ainda é pouco conhecida e quantificada. 
O PD promove inúmeros benefícios, entre estes, maior teor de matéria orgânica e agregação do solo (URI, 2000; BLANCO-CANQUI et al., 2010; HOLANDA et al., 2011), reduz os custos de produção, a erosão hídrica, eutrofização das águas dos mananciais hídricos e a degradação do solo, devido à ausência de revolvimento e à contínua deposição e manutenção de resíduos vegetais em superfície (URI, 2000).

Neste sentido, o objetivo deste trabalho foi avaliar o efeito de sistemas de manejo, da palha residual e do uso anterior na produtividade de arroz irrigado por inundação.

\section{Material e Métodos}

Os experimentos foram realizados nas coordenadas $29^{\circ} 40^{\prime} 55^{\prime \prime} \mathrm{S}$ e $56^{\circ} 38^{\prime} 17^{\prime \prime} \mathrm{W}$, em Uruguaiana, RS, em altitude de $100 \mathrm{~m}$, em Neossolo Litólico (EMBRAPA, 2006) com 7\% de declividade. O clima é do tipo Cfa, segundo Köppen-Geiger.

Foi realizado um conjunto de três experimentos (E) em delineamento inteiramente casualizado que consistiram na comparação dos tratamentos PC e PD. O E1 e E2 tiveram 10 repetições e o E3 foi feito com 6 repetições (parcelas de $3 \mathrm{~m} \mathrm{x} 2$ $\mathrm{m})$. Os experimentos foram: E1 - constituído dos tratamentos, sistema plantio direto (E1PD) e sistema convencional com duas gradagens na camada de 0,0 - 0,07 m + aplainamento com remaplam (E1PC), em área de três anos de cultivo de arroz em PD, após pousio do cultivo de arroz e semeadura de azevém no inverno, com pastejo animal o ano todo, durante sete anos; E2 - sistema plantio direto (E2PD) e sistema convencional (E2PC), após campo nativo utilizado como pastagem para bovinos; E3 - plantio direto em área com ausência de palha na superfície do solo (E30P), palha atual na superfície do solo de $3.726 \mathrm{~kg} \mathrm{ha}^{-1}(\mathrm{E} 31 \mathrm{P})$, duas vezes a quantidade de palha atual, $7.452 \mathrm{~kg} \mathrm{ha}^{-1}(\mathrm{E} 32 \mathrm{P})$ e três vezes a quantidade de palha atual, $11.178 \mathrm{~kg} \mathrm{ha}^{-1}(\mathrm{E} 33 \mathrm{P})$. No E3, no tratamento E30P, foi retirada toda a palha da superfície do solo, a qual foi aplicada na superfície do tratamento E32P, correspondente a duas vezes a quantidade de palha sobre a superfície do solo e, no E33P foi adicionado palha retirada de áreas próximas, visto que cada parcela teve delimitação por camalhões e entrada individual de água.

O E1 e o E3 foram instalados em área com o mesmo manejo nos anos anteriores, $500 \mathrm{~m}$ de distância entre estes, sendo o E3 em local mais baixo do relevo. No inverno as áreas ficaram em pousio e a soca do arroz utilizada para pastoreio com lotação animal inferior a 1,2 unidades animal por hectare.

A composição granulométrica, na camada de $0,0-0,20 \mathrm{~m}$, determinada pelo método da pipeta (EMBRAPA, 1997), foi de: 229, 662 e $109 \mathrm{~g} \mathrm{~kg}^{-1}$, no E1; 249, 540 e $211 \mathrm{~g} \mathrm{~kg}^{-1}$, no E2; 215, 658 e 127 $\mathrm{g} \mathrm{kg}^{-1}$, no E3 (correspondentes a argila, silte e areia, respectivamente). A composição química do solo foi determinada na camada de $0,0-0,20 \mathrm{~m}$, no PD e PC e, está apresentada na tabela 1.

Tabela 1. Caracterização química do solo, no PD e PC, nos experimentos 1, 2 e 3 (E1, E2 e E3), antes da semeadura do arroz.

\begin{tabular}{lccccccc}
\hline Tratamento & $\mathrm{pH}\left(\mathrm{H}_{2} \mathrm{O}\right)$ & $\mathrm{MO}$ & $\mathrm{Ca}$ & $\mathrm{Mg}$ & $\mathrm{K}$ & $\mathrm{P}($ Mehlich $)$ & $\mathrm{V}$ \\
\hline & & $\%$ & $-------\mathrm{cmol}_{\mathrm{c}} \mathrm{dm}^{-3}------$ & $\mathrm{mg} \mathrm{dm}^{-3}$ & $\%$ \\
E1PD & 4,7 & 5,1 & 13,9 & 5,0 & 0,31 & 6,0 & 80 \\
E1PC & 4,7 & 5,0 & 12,4 & 4,0 & 0,45 & 7,6 & 77 \\
E2PD & 4,7 & 5,1 & 17,2 & 6,4 & 0,17 & 3,7 & 75 \\
E2PC & 4,8 & 5,1 & 17,5 & 6,5 & 0,16 & 3,7 & 78 \\
E3 & 5,0 & 5,1 & 11,2 & 4,5 & 0,36 & 6,8 & 74 \\
\hline
\end{tabular}

E1 e E3= Área com três anos de plantio direto de arroz, após pousio do cultivo de arroz e semeadura de azevém no inverno, com pastejo animal o ano todo; $\mathrm{E} 2=$ Área de campo nativo. $\mathrm{PD}=$ plantio direto; $\mathrm{PC}=$ sistema convencional com utilização de duas gradagens na profundidade de $0,0-0,07 \mathrm{~m}+$ remaplam.

Fonte: Elaboração dos autores. 
Em agosto de 2011, foi preparado o solo no PC, sendo construídas e remontadas as taipas no sistema PD, com camalhão de 0,12 m de altura e dimensionamento entre taipas suficiente para permitir uma lâmina de água de $\pm 0,04 \mathrm{~m}$ de altura sobre o solo, a qual foi aplicada 20 dias após a emergência do arroz.

Antes da semeadura foram aplicados herbicidas e foi avaliada a quantidade de massa seca na superfície do solo em área de $0,25 \mathrm{~m}^{2}$ por repetição.

A semeadura foi realizada dia 15 de setembro no E2 e dia 20 de outubro no E1 e E3, variedade IRGA 424, na densidade de 60 sementes por metro e no espaçamento de $0,17 \mathrm{~m}$ entre linhas. A adubação foi de $240 \mathrm{~kg} \mathrm{ha}^{-1}$ de 09-23-30 N-P-K, na semeadura; $100 \mathrm{~kg} \mathrm{ha}^{-1}$ de uréia e $80 \mathrm{~kg} \mathrm{ha}^{-1}$ de cloreto de potássio 20 dias após a semeadura, antes da entrada da água; $60 \mathrm{~kg} \mathrm{ha}^{-1}$ de 30-00-20 N-P-K na diferenciação do primórdio floral.

Após a semeadura foram coletadas uma amostra indeformada por parcela, na entrelinha, para avaliação do diâmetro médio geométrico dos agregados (DMG) na camada de 0,0-0,05 m e, a densidade do solo (Ds), porosidade total, macro e microporosidade em amostras indeformadas coletadas com cilindros de $0,05 \mathrm{~m}$ de diâmetro e $0,03 \mathrm{~m}$ de altura, nas camadas de $0,0-0,05$ e $0,05-$ $0,10 \mathrm{~m}$, cujas determinações seguiram metodologia de EMBRAPA (1997).

$\mathrm{Na}$ colheita, foram avaliados, em cada parcela, o número de panículas em área de $0,25 \mathrm{~m}^{2}$, número de grãos cheios, vazios e total em 10 panículas, massa de mil sementes e a produtividade de grãos de arroz com $12 \%$ de umidade, em área de $2 \mathrm{~m}^{2}$.
A análise de variância foi realizada em cada experimento individualmente e as diferenças entre as médias foram testadas pelo Teste de Tukey $(\mathrm{p}<$ $0,05)$.

\section{Resultados e Discussão}

O manejo do solo alterou as propriedades físicas do solo: DMG, Ds, macro, micro e porosidade total (Tabela 2). O DMG dos agregados do solo foi inferior no sistema de PC, na camada de 0,0-0,05 m em função do revolvimento do solo com gradagens antes da semeadura, desestruturando o solo, corroborando com Oliveira et al. (2004) e Costa et al. (2009) que também verificaram valores inferiores no PC. Porém, os valores de DMG encontrados são elevados, comparado a solos com baixos teores de matéria orgânica (MO), em áreas de sequeiro, conforme verificado por Wendling et al. (2005). Em Latossolo Vermelho argiloso e com altos teores de MO, na camada de 0,0 a 0,05 m, Oliveira et al. (2004) verificaram valores de DMG acima de 3,3 mm, em sistemas com 20 anos de manejo do solo. Costa et al. (2009) também verificaram valores de DMG próximo a $5 \mathrm{~mm}$ em Cambissolo com altos teores de MO. Os altos valores de DMG, acima de 3,36 mm, devem-se aos elevados teores de matéria orgânica (5\%), que promovem maior agregação (OLIVEIRA et al., 2004; BLANCO-CANQUI et al., 2010) e a expressiva quantidade de minerais de argila 2:1 nesse solo (PEDRON, 2007), que promovem maior coesão e agregação. O maior DMG é benéfico, pois minimiza as perdas de solo por erosão hídrica, visto que este solo utilizado para o cultivo de arroz apresenta uma melhor agregação e resistência à degradação. 
Tabela 2. Diâmetro médio geométrico dos agregados (DMG), densidade do solo (Ds), macroporosidade (Ma), microporosidade (Mi) e porosidade total ( $\mathrm{Pt}$ ), nos experimentos 1 e 2 (E1 e E2) e nas profundidades de 0,0-0,05 m e 0,05-0,10 m, em sistemas de manejo.

\begin{tabular}{|c|c|c|c|c|c|}
\hline Tratamento & DMG & Ds & $\mathrm{Ma}$ & $\mathrm{Mi}$ & $\mathrm{Pt}$ \\
\hline & $\mathrm{mm}$ & $\mathrm{Mg} \mathrm{m}^{-3}$ & \multicolumn{3}{|c|}{--------------- $\mathrm{m}^{3}$ m³ } \\
\hline \multicolumn{6}{|c|}{$0,0-0,05 \mathrm{~m}$} \\
\hline E1PD & $4,58 \mathrm{a}$ & $1,07 \mathrm{a}$ & $0,05 \mathrm{~b}$ & $0,48 \mathrm{a}$ & $0,53 \mathrm{~b}$ \\
\hline E1PC & $3,61 \mathrm{~b}$ & $1,05 \mathrm{a}$ & $0,10 \mathrm{a}$ & $0,46 \mathrm{~b}$ & $0,56 \mathrm{a}$ \\
\hline E2PD & $4,85 \mathrm{a}$ & $1,10 \mathrm{a}$ & $0,12 \mathrm{~b}$ & $0,44 \mathrm{a}$ & $0,56 \mathrm{~b}$ \\
\hline E2PC & $3,36 \mathrm{~b}$ & $0,88 \mathrm{~b}$ & $0,21 \mathrm{a}$ & $0,39 \mathrm{~b}$ & $0,59 \mathrm{a}$ \\
\hline \multicolumn{6}{|c|}{$0,05-0,10 \mathrm{~m}$} \\
\hline E1PD & -- & $1,18 \mathrm{~b}$ & $0,04 \mathrm{~b}$ & $0,45 \mathrm{a}$ & $0,48 \mathrm{~b}$ \\
\hline E1PC & -- & $1,23 \mathrm{a}$ & $0,06 \mathrm{a}$ & $0,44 \mathrm{a}$ & $0,51 \mathrm{a}$ \\
\hline E2PD & -- & $1,17 \mathrm{a}$ & $0,11 \mathrm{~b}$ & $0,44 \mathrm{a}$ & $0,54 \mathrm{~b}$ \\
\hline E2PC & -- & $0,97 \mathrm{~b}$ & $0,17 \mathrm{a}$ & $0,41 \mathrm{a}$ & $0,59 \mathrm{a}$ \\
\hline
\end{tabular}

Médias seguidas de letras iguais, na mesma camada de solo e, no mesmo experimento, não diferem entre si, pelo teste de Tukey, a 5\% de probabilidade. Experimento 1 (E1), sistema plantio direto (E1PD) e sistema convencional com duas gradagens na profundidade de $0,0-0,07 \mathrm{~m}+$ remaplam (E1PC), em área de três anos de cultivo de arroz após pousio do cultivo de arroz e semeadura de azevém no inverno, com pastejo animal o ano todo; experimento 2 (E2), sistema plantio direto (E2PD) e sistema convencional (E2PC), após campo nativo. -- Não determinado.

Fonte: Elaboração dos autores.

A densidade do solo foi inferior no E2, nas camadas de 0,0-0,05 e 0,05-0,10 $\mathrm{m}$ de profundidade, no PC comparado ao PD, em função do revolvimento do solo, e no E1 não houve diferença na camada de 0,0-0,05 m. A macroporosidade e a porosidade total foram inferiores no PD nas camadas de 0,00,05 e 0,05-0,10 m, no E1 e E2, indicando uma compactação no $\mathrm{PD}$, com valores inferiores a 0,11 $\mathrm{m}^{3} \mathrm{~m}^{-3}$ de macroporosidade, considerados baixos, visto que o crescimento das plantas é reduzido em valores de porosidade de aeração superiores, em culturas de sequeiro (SILVA; IMHOFF; KAY, 2004). Por outro lado, verifica-se que os valores de porosidade total estão próximos a $0,50 \mathrm{~m}^{3} \mathrm{~m}^{-3}$, com altos valores de microporosidade, inerentes ao tipo de solo com expressiva quantidade de minerais 2:1 na fração argila que ocorre na região da fronteira oeste do Estado do Rio Grande do Sul (PEDRON, 2007), que promove esse comportamento estrutural mais coeso e menor macroporosidade.

O manejo do solo em PC ou em PD alteraram as propriedades físicas do solo, porém, isto não refletiu nos componentes de rendimento e na produtividade de arroz irrigado por inundação (Tabelas 3, 4 e 5).
Isto porque no sistema de cultivo de arroz irrigado, a inundação é realizada 20 dias após a germinação, no início do desenvolvimento do sistema radicular e das plantas, tornando a influência das propriedades físicas e da compactação do solo pouco expressiva. No solo alagado ocorre diminuição da coesão entre as partículas e esse apresenta uma consistência semifluida e com pouca resistência à penetração (BRADY; WEIL, 2008), permitindo o pleno crescimento das raízes no interior do solo. Ainda, em relação à aeração, o arroz possui aerênquimas que permitem seu desenvolvimento em condições de deficiência de aeração (SOSBAI, 2010). Desta forma, a Ds, porosidade e aeração tem pouca influência na produtividade de arroz irrigado por inundação, justificando a mesma produtividade no PC e PD. Resultados semelhantes foram encontrados por Beutler et al. (2012), em que o sistema de manejo não promoveu alteração na produtividade de arroz irrigado por inundação. Medeiros, Soares e Guimarães (2005) também encontraram pouca influência da compactação do solo na produtividade de arroz e que essa não é fator limitante à adoção do sistema PD em solos de várzeas. 
Em relação aos sistemas PC e PD, a incorporação de arroz irrigado, possivelmente em razão da ou a manutenção da palha na superfície, pequena quantidade de restos culturais do arroz, respectivamente, na quantidade de 5.044 a 5.197 visto que quantidades maiores causam redução na $\mathrm{kg} \mathrm{ha}^{-1}$, no E1 e E2, também não influenciaram nos produtividade de grãos, conforme Camargo et al. componentes de rendimento e na produtividade (1995).

Tabela 3. Número de panículas, grãos cheios por panícula, grãos vazios por panícula, total de grãos por panícula e massa de mil sementes de arroz, nos experimentos 1, 2 e 3 (E1, E2 e E3), em sistemas de manejo.

\begin{tabular}{|c|c|c|c|c|c|}
\hline Tratamento & $\begin{array}{l}\text { Número de } \\
\text { panículas }\end{array}$ & $\begin{array}{l}\text { Grãos cheios } \\
\text { por panícula }\end{array}$ & $\begin{array}{l}\text { Grãos vazios por } \\
\text { panícula }\end{array}$ & $\begin{array}{l}\text { Total de grãos por } \\
\text { panícula }\end{array}$ & $\begin{array}{l}\text { Massa de mil } \\
\text { sementes }\end{array}$ \\
\hline & $\mathrm{m}^{2}$ & & & & $\mathrm{~g}$ \\
\hline \multicolumn{6}{|c|}{ Experimento 1} \\
\hline E1PD & $690 \mathrm{a}$ & $73 \mathrm{a}$ & $17 \mathrm{a}$ & $90 \mathrm{a}$ & $25 \mathrm{a}$ \\
\hline E1PC & $683 \mathrm{a}$ & $80 \mathrm{a}$ & $16 \mathrm{a}$ & $96 \mathrm{a}$ & $25 \mathrm{a}$ \\
\hline \multicolumn{6}{|c|}{ Experimento 2} \\
\hline E2PD & $636 \mathrm{a}$ & $83 \mathrm{a}$ & $8 a$ & $94 \mathrm{a}$ & $25 \mathrm{a}$ \\
\hline E2PC & $581 \mathrm{a}$ & $79 a$ & $8 a$ & $87 \mathrm{a}$ & $25 \mathrm{a}$ \\
\hline \multicolumn{6}{|c|}{ Experimento 3} \\
\hline E30P & $583 \mathrm{a}$ & $73 \mathrm{a}$ & $19 \mathrm{a}$ & $92 \mathrm{a}$ & $25 \mathrm{a}$ \\
\hline E31P & $573 a$ & $70 \mathrm{a}$ & $11 \mathrm{~b}$ & $81 \mathrm{a}$ & $25 \mathrm{a}$ \\
\hline E32P & $565 \mathrm{a}$ & $84 \mathrm{a}$ & $11 \mathrm{~b}$ & $95 \mathrm{a}$ & $25 \mathrm{a}$ \\
\hline E33P & $569 \mathrm{a}$ & $71 \mathrm{a}$ & $11 \mathrm{~b}$ & $82 \mathrm{a}$ & $25 \mathrm{a}$ \\
\hline
\end{tabular}

Médias seguida da mesma letra minúsculas, na coluna e no mesmo experimento, não diferem entre si pelo teste de Tukey ( $\mathrm{p}<0,05)$. Experimento 1 (E1), sistema plantio direto (E1PD) e sistema convencional com duas gradagens na profundidade de $0,0-0,07 \mathrm{~m}+$ remaplam (E1PC), em área de três anos de cultivo de arroz após pousio do cultivo de arroz e semeadura de azevém no inverno, com pastejo animal o ano todo; experimento 2 (E2), sistema plantio direto (E2PD) e sistema convencional (E2PC), após campo nativo; experimento 3 (E3), PD e ausência de palha na superfície do solo (E30P), palha atual na superfície do solo (E31P), duas vezes a quantidade de palha atual (E32P) e três vezes a quantidade de palha atual (E33P).

Fonte: Elaboração dos autores.

Tabela 4. Análise de variância da produtividade de grãos de arroz irrigado no E1, E2 e E3.

\begin{tabular}{|c|c|c|c|c|}
\hline Causas variação & GL & SQ & $\mathrm{QM}$ & $\mathrm{F}$ \\
\hline \multicolumn{5}{|l|}{ Experimento 1} \\
\hline Tratamentos & 1 & 1762297,5224 & 1762297,5224 & $0,23^{\text {ns }}$ \\
\hline Resíduo & 18 & 135830400,6207 & 7546133,3678 & \\
\hline Total & 19 & 137592698,1431 & & \\
\hline $\begin{array}{l}\text { Tratamentos } \\
\text { Resíduo } \\
\text { Total }\end{array}$ & $\begin{array}{c}1 \\
18 \\
19\end{array}$ & $\begin{array}{c}\text { Experimento } 2 \\
645924,4646 \\
26825542,9004 \\
27471467,3651\end{array}$ & $\begin{array}{c}645924,4646 \\
1490307,9389\end{array}$ & $0,43^{\text {ns }}$ \\
\hline Total & & Experimento 3 & & \\
\hline Tratamentos & 3 & 4649760,3677 & 1549920,1226 & $1,45^{\text {ns }}$ \\
\hline Resíduo & 20 & 21395661,7875 & 1069783,0894 & \\
\hline Total & 23 & 26045422,1552 & & \\
\hline
\end{tabular}

ns Não significativo.

Fonte: Elaboração dos autores. 
Tabela 5. Quantidade de massa seca na superfície do solo (MS), antes da semeadura, e produtividade de grãos de arroz irrigado por inundação, nos experimentos 1, 2 e 3 (E1, E2 e E3), em sistemas de manejo.

\begin{tabular}{|c|c|c|}
\hline \multirow[t]{2}{*}{ Tratamento } & MS na superfície do solo & Produtividade de grãos de arroz \\
\hline & \multirow{2}{*}{\multicolumn{2}{|c|}{ Experimento 1}} \\
\hline & & \\
\hline E1PD & $5.044 \mathrm{a}$ & $11.777 \mathrm{a}$ \\
\hline \multirow{2}{*}{ E1PC } & $3.202 \mathrm{~b}$ & $11.371 \mathrm{a}$ \\
\hline & \multicolumn{2}{|c|}{ Experimento 2} \\
\hline E2PD & $5.197 \mathrm{a}$ & $9.778 \mathrm{a}$ \\
\hline $\mathrm{E} 2 \mathrm{PC}$ & $373 \mathrm{~b}$ & $9.418 \mathrm{a}$ \\
\hline & \multicolumn{2}{|c|}{ Experimento 3} \\
\hline E30P & 0 & $10.590 \mathrm{a}$ \\
\hline E31P & 3.726 & $9.759 \mathrm{a}$ \\
\hline E32P & 7.452 & $9.710 \mathrm{a}$ \\
\hline E33P & 11.178 & $9.403 \mathrm{a}$ \\
\hline
\end{tabular}

Médias seguida da mesma letra minúsculas, na coluna e no mesmo experimento, não diferem entre si pelo teste de Tukey ( $\mathrm{p}<0,05$ ). Experimento 1 (E1), sistema plantio direto (E1PD) e sistema convencional com duas gradagens na profundidade de $0,0-0,07 \mathrm{~m}+$ remaplam (E1PC), em área de três anos de cultivo de arroz após pousio do cultivo de arroz e semeadura de azevém no inverno, com pastejo animal o ano todo; experimento 2 (E2), sistema plantio direto (E2PD) e sistema convencional (E2PC), após campo nativo; experimento 3 (E3), PD e ausência de palha na superfície do solo (E30P), palha atual na superfície do solo (E31P), duas vezes a quantidade de palha atual (E32P) e três vezes a quantidade de palha atual (E33P).

Fonte: Elaboração dos autores.

No E3, o PD com quantidade de palha residual de arroz na superfície do solo de 0 a $11.178 \mathrm{~kg} \mathrm{ha}$ ${ }^{1}$, não evidenciou diferença nos componentes de rendimento e na produtividade de arroz irrigado por inundação, em área com 7\% de declividade, corroborando os resultados obtidos por Beutler et al. (2012). Estes autores verificaram que a quantidade de palha de arroz na superfície do solo de até $24.588 \mathrm{~kg} \mathrm{ha}^{-1}$ não reduziram a produtividade de arroz irrigado por inundação, em PD, em área com $4 \%$ de declividade. Estes resultados permitem inferir que a produtividade de arroz não é reduzida em decorrência da decomposição anaeróbica da palha na superfície do solo, quando ocorre pequeno fluxo de água na superfície, em quantidades de palha encontradas nas lavouras de arroz. Por outro lado, Camargo et al. (1995) verificaram que a produtividade máxima de grãos de arroz foi obtida com 6,5 $\mathrm{t} \mathrm{ha}^{-1}$ de palha de arroz moída e incorporada em Gleissolo, cujo fracionamento acelera a decomposição pelo maior contato dos microorganismos com a palha, em vasos com água estagnada. No entanto, até $20 \mathrm{tha}^{-1}$ de palha ocorreu uma pequena redução de $7 \%$ na produtividade de grãos, sendo os efeitos mais acentuados com $40 \mathrm{t}$ $\mathrm{ha}^{-1}$ de palha, que reduziu $45,8 \%$ a produtividade.

No cultivo do arroz em condições de campo, geralmente, ocorre um fluxo superficial de água que dilui o efeito dos ácidos orgânicos produzidos pela palha do arroz em decomposição anaeróbica devido ao alagamento do solo, em função do carreamento e dispersão desses, diluindo o efeito prejudicial que pode causar redução da produtividade de grãos (SWAROWSKY et al., 2006). Essa redução da produtividade ocorre em função dos ácidos orgânicos voláteis, produzidos durante a decomposição anaeróbica da palha, que interferem na absorção de nutrientes, perfilhamento, produção de massa seca, número de panículas e esterilidade de flores culminando com a redução da produtividade de grãos de arroz (CAMARGO et al., 2001)

Utilizou-se o mesmo genótipo de arroz nos 3 experimentos. No entanto, a produtividade de arroz foi inferior no E2 comparado ao E1, em razão da ocorrência de granizo no E2. Já no E3, 
em área distante a $500 \mathrm{~m}$ do $\mathrm{E} 1$ e com o mesmo manejo de solo, a produtividade foi inferior em razão da menor disponibilidade de água no E3, em razão das estiagens que induziram a necessidade de racionamento de água na área, visto que os experimentos foram instalados em área comercial de arroz.

Os resultados obtidos nesse estudo, nos trabalhos de Camargo et al. (1995) e Beutler et al. (2012), suportam a hipótese da viabilidade do PD em arroz irrigado por inundação e que a palha de arroz, em quantidades encontradas em condições de campo, tem pouca influência na redução da produtividade de grãos de arroz.

\section{Conclusões}

O sistema de manejo convencional apresenta menor estabilidade de agregados, maior macroporosidade e porosidade total do solo, comparado ao sistema plantio direto, porém, não resulta em diferença nos componentes de produção e produtividade de grãos de arroz irrigado.

O manejo do solo em sistema plantio direto, com a quantidade de palha de arroz na superfície do solo de até $11.178 \mathrm{~kg} \mathrm{ha}^{-1}$, antes da semeadura, não reduz a produtividade de grãos de arroz irrigado por inundação.

\section{Agradecimentos}

Ao Técnico Agrícola da Fazenda Fonte Rica, Geri Munareto, pela cessão da área e auxílio na execução dos experimentos. Ao $\mathrm{CNPq}$ pela concessão das bolsas ao primeiro e segundo autor e a Fapergs pela concessão da bolsa ao terceiro autor.

\section{Referências}

BEUTLER, A. N.; MUNARETO, J. D.; RAMÃO, C. J.; GALON, L. DIAS, N. P.; POZZEBON, B. C.; RODRIGUES, L. A. T.; MUNARETO, G. S.; GIACOMELI, R.; RAMOS, P. V. Propriedades físicas do solo e produtividade de arroz irrigado em diferentes sistemas de manejo. Revista Brasileira de Ciência do Solo, Viçosa, MG, v. 36, n. 5, p. 1083-1091, 2012.

BLANCO-CANQUI, H.; STONE, L. R.; SCHLEGEL, A. J.; BENJAMIN, J. G.; VIGIL, M. F.; STAHLMAN, P. W. Continuous cropping systems reduce near-surface maximum compaction in no-till soils. Agronomy Journal, Madison, v. 102, n. 4, p. 1217-1225, 2010.

BRADY, N. C.; WEIL, R. R. The nature and properties of soils. 14. ed. New Jersey: Pearson Prentice Hall, 2008. $975 \mathrm{p}$.

CAMARGO, F. A. de O.; SANTOS, G. de A.; ROSSIELLO, R. O. P.; ZONTA, E. Incorporação de palha de arroz em um Gleissolo e efeitos no rendimento da cultura do arroz irrigado. Pesquisa Agropecuária Brasileira, Brasília, v. 30, n. 7, p. 983-987, 1995.

CAMARGO, F. A. de O.; ZONTA, E.; SANTOS, G. de A.; ROSSIELLO, R. O. P. Aspectos fisiológicos e caracterização da toxidez de ácidos orgânicos voláteis em plantas. Ciência Rural, Santa Maria, v. 31, n. 3, p. 523-529, 2001.

COSTA, A. da; ALBUQUERQUE, J. A.; MAFRA, Á. L.; SILVA, F. R. da. Propriedades físicas do solo em sistemas de manejo na integração agricultura-pecuária. Revista Brasileira de Ciência do Solo, Viçosa, MG, v. 33, n. 2, p. 235-244, 2009.

EMPRESA BRASILEIRA DE PESQUISA AGROPECUÁRIA - EMBRAPA. Centro Nacional de Pesquisa de Solos. Sistema brasileiro de classificação de solos. Rio de Janeiro: Embrapa, 1997. 212 p.

Manual de métodos de análise de solo. Rio de Janeiro: Embrapa, 2006. 306 p.

HOLANDA, F. S. R.; PEDROTTI, A.; MENGEL, D. B.; CARVALHO, J. G. de; SILVA, R. O. da; JUNIOR, A. V. M. Contribuição do sistema de cultivo sobre a matéria orgânica de um Gleissolo e a produtividade do milho e soja. Semina: Ciências Agrárias, Londrina, v. 32, n. 3, p. 983-994, 2011.

JOHNSON, S. E.; ANGELES, O. R.; BRAR, D. S.; BURESH, R. J. Faster anaerobic decomposition of a brittle straw rice mutant: implications for residue management. Soil Biology and Biochemistry, Oxford, v. 38, n. 7, p. 1880-1892, 2006.

MEDEIROS, R. D. de; SOARES, A. A.; GUIMARÃES, R. M. Efeitos da compactação do solo e do manejo da água sobre os componentes de produção e a produtividade de grãos de arroz. Ciência e Agrotecnologia, Lavras, v. 29, n. 5, p. 960-967, 2005. 
OLIVEIRA, G. C.; DIAS JUNIOR, M. S.; RESCK, D. V. S.; CURI, N. Caracterização química e físico-hídrica de um Latossolo Vermelho após vinte anos de manejo e cultivo do solo. Revista Brasileira de Ciência do Solo, Viçosa, MG, v. 28, n. 2, p. 327-336, 2004.

PEDRON, F. de A. Mineralogia, morfologia e classificação de saprólitos e Neossolos derivados de rochas vulcânicas no Rio Grande do Sul. 2007. Tese (Doutorado em Ciência do Solo) - Universidade Federal de Santa Maria, Santa Maria.

SILVA, A. P. da; IMHOFF, S.; KAY, B. Plant response to mechanical resistance and air-filled porosity of soils under conventional and no-tillage system. Scientia Agrícola, Piracicaba, v. 61, n. 4, p. 451-456, 2004.

SILVA, S. G. C.; SILVA, A. P.; GIAROLA, N. F. B; TORMENA, C. A.; SÁ, J. C. de M. Temporary effect of chiseling on the compaction of a rhodic hapludox under no-tillage. Revista Brasileira de Ciência do Solo, Viçosa, MG, v. 36, n. 2, p. 547-555, 2012.

SOCIEDADE SUL-BRASILEIRA DE ARROZ IRRIGADO - SOSBAI. Arroz irrigado: recomendações técnicas da pesquisa para o Sul do Brasil. Porto Alegre: Palotti, 2010. 188 p.
SOUSA, R. O. de; BORTOLON, L. Crescimento radicular e da parte aérea do arroz (Oryza sativa L.) e absorção de nutrientes, em solução nutritiva com diferentes concentrações de ácido acético. Revista Brasileira de Agrociência, Pelotas, v. 8, n. 3, p. 231-235, 2002.

SWAROWSKY, A.; RIGHES, A. A.; MARCHEZAN, E.; RHODEN, A. C.; GUBIANI, E. I. Concentração de nutrientes na solução do solo sob diferentes manejos do arroz irrigado. Revista Brasileira de Engenharia Agrícola e Ambiental, Campina Grande, v. 10, n. 2, p. 344-351, 2006.

URI, N. D. Perceptions on the use of no-till farming in production agriculture in the United States: an analysis of survey results. Agriculture, Ecosystems \& Environment, Philadelphia, v. 77, n. 3, p. 263-266, 2000.

WENDLING, B.; JUCKSCH, I.; MENDONÇA, E. de S.; NEVES, J. C. L. Carbono orgânico e estabilidade de agregados de um Latossolo Vermelho sob diferentes manejos. Pesquisa Agropecuária Brasileira, Brasília,v. 40, n. 5, p. 487-494, 2005. 
